\title{
Improving Mother's Care of Low Birth Weight at Home
}

\author{
Manal Abd El-Salam, Nawal Mahmoud Soliman, Magda A. Ahmed, \\ Department of Community Nursing - Faculty of Nursing, Ain Shams University - Egypt
}

\begin{abstract}
Low birth weight infants are a special group that needs attention and care. The study aims to improve mother's care of low birth weight infants at home. Research design: It is A quasiexperimental design were used in this study. Setting: This study were conducted at Neonatal Intensive Care Unit (NICU) of Ain Shams Maternity Hospital and at mother's home. Sampling: A purposeful sample were used in this study, $20 \%$ of total admitted rate equal to 122 of mothers of low birth weight infant and were chosen randomly according to criteria. Tools: Two tool were used for data collection, An interviewing questionnaire for mothers to assess their socio demographic characteristics and their knowledge, checklist to assess mothers' practices, and Observational checklist for assessing home environment. Results: The study showed highly statistically significance differences between the mother's socio-demographic and their knowledge and practice, highly statistically significance positive correlation between mothers and their practice and knowledge. Recommendation: the study recommended to conduct an educational program for the high risk pregnant women in the follow up clinic to raise their knowledge and practices related to their low birth weight infant..
\end{abstract}

Key words: Low birth weight, Home care.

\section{Introduction}

Low birth weight infants (LBW) are the infants who born less than 2.500 grams, it is the most significant factor contributing to neonatal morbidity and mortality. Conventional neonatal care of LBW infants is expensive and needs both highly skilled personnel and permanent logistic support(Stoll\&AdamsChapman, 2009).

Worldwide, low birth weight infant is linked to more than $77 \%$ of stillbirths and $75 \%$ of deaths among newly-born babies. At least, 10 million infants are born low weight each year globally, and more than a million of them die. Africa has the highest rate of low birth weight infants at $14 \%$, but the United States is close behind at $9 \%$. Europe has the lowest rate at $4 \%$. Low birth weight infants are the second leading cause of infant mortality in Africa. after birth defects (The National Center for Health Statistics, 2015)

Mothers of low birth weight infants involve responsibilities such as preventing infection, transitioning to new sleeping patterns, dealing with feeding difficulties and managing continued health problems. However, mothers of LBW infants need to receive instructions about prevention of infections and care of minor acute illness before discharge from the neonatal intensive care unit. (Kairamkonda, 2013). 
Significance of the study :-

In Egypt The incidence of low birth weight, of newborns weighing less than 2,500 grams, is monitored through both health system surveillance and household surveys. In 2013, nearly 22 million newborns - an estimated 16 per cent of all babies born globally that year-had low birth weight. Accurate monitoring is challenging, however, since nearly half of the world's infants are not weighed at birth, A baby's weight at birth is a strong indicator of maternal and newborn health and nutrition (Ministry of health,2010).

In Egypt, prevalence of LBW babies is suggested to be $2.1 \%$ of all deliveries in Cairo city. Further, prevalence of LBW is found to be $8.8 \%$ of unfavorable pregnancy outcomes (ElHouseinie et al., 2014)

\section{Causes of Low Birth Infant}

The exact causes of L.B.W are not known . However, all of the factors that place a pregnancy at risk should be considered potential causes of complications for the new born infant as well whenever, difficulty during pregnancy may lead to L.B.W infant. (Wong, 2013).

\section{Home Care}

Successful transition of the L.B.W infant from hospital to home care requires a through understanding of the identified criteria for discharge, coordination and progression of activities that ready the infant and mother for home, appropriate identification and referral for communitybased services and both the psychological and physical preparation required as mothers accept their role as independent care gives (Deacon, 2013).
The nurse should emphasize the protective care of the infant in the home environment, stressing principles of safety and hygiene throughout the teaching, after discharge from the hospital, the nurse should visit the mother in her home before this time in order to familiarize her with baby care, to evaluate the home environment and the availability of needed equipment for care, and to evaluate parental feelings about the infant(Opportunities for Africa's Newborn 2011).

\section{Aim of the study}

The study aims to evaluate the health education program for improving of mother's care of low birth weight infants at home.

\section{Research Hypothesis:-}

Implementation of program will improve the mothers to care for their neonate with low birth weight at home.

\section{Subject and methods:}

Research design: This is quasi experimental design to used in this study.

\section{Setting}

This study were conducted at Neonatal Intensive Care Unit (NICU) of Ain Shams Maternity Hospital and at mother's home.

\section{Sampling}

A purposeful sample were used in this study, The total number of Low birth weight babies were 610 in Obstetrics\& Gynecological Hospital - Ain Shams University Hospitals( NICU department ) in $2013 \& 2014,20 \%$ of total admitted rate equal to 122 of mothers of low birth 
weight infant and will be chosen randomly according to criteria.

\section{Technical design}

Tools of data collection data

Three tool were used for collecting

First tool An interviewing questionnaire will be designed by the investigator in simple Arabic language after undertaken a literature review ,It included the following parts:

a) Characteristics of Low birth weight infants as

(sex-birth-weight-gestational age and birth order).

b) Characteristics of mothers such as age, level of education and employment.

c) Maternal and Obstetrical history as regards information about antenatal care, disease way of delivery parity, past obstetrical history including previous Low birth weight infant deaths, maternal medical history and obstetrical history during her pregnancy.

d) Mother's knowledge regarding care of their Low birth weight infants (sleeping ,nutrition, immunization , feeding position, growth and development).

Second Tool: An observation Checklist to assess:

a) Mother 's Practices Checklist such as eye care, cord care, diaper care, bathing, measuring axillary temperature, breast feeding technique and bottle feeding technique, the tool used before and after the program. b) Home environment Checklist such as refrigerators, medicines and poisonous household substances, safe toys free lead paints, removed sharp objects from infants reach, cap electrical outlets and used firm mattress, bed with sides.

Third Tool: Medical Record analysis of mothers and neonates regarding diagnosis, health problems, Apgar scoring, type of delivery, investigation and complication.

\section{Collection of the sample:}

Interviewing was collected from 122 mothers in neonate intensive care unit after explaining to them the purpose of the study. The time needed to complete the questionnaire sheet was 30-45 minutes.

\section{Ethical considerations:}

The study used numbers for identification of participants and the responses of the mothers were kept confidential. Prior to the pilot study, ethical approval will be obtained from the Scientific Research Ethical Committee of Ain Shams University.

In addition written informed consent obtained from each participant, they assured that confidentiality would be guaranteed and the right to with draw from the study at any time.

\section{Operational design}

\section{Pilot study}

The pilot study conducted to test the effectiveness, clarity and time availability, According to the results of the pilot study, the necessary modifications such as omission, addition and rewording were done 


\section{Field work :}

Approval from the administrator of Obstetrics\& Gynecological Hospital Ain Shams University Hospitals.

Preparing Three tools were used for collecting data

collect the data through three days per week during morning shift from (8am: 2pm).

program construction:-The present study was conducting in four phases:

First phase; preparatory:

A review of recent, current, national and international related literature in various aspects of the problem was done at this phase .It's aim is to design the study tools and to be acquainted with various aspects of the problem and health educational program.

Second phase ; the assessment: By using pretest questionnaire based on the assessment phase.

Third phase ; the planning and implementing of educational program: In This phase to develop the program and its implementation.

\section{program \\ Objective of health educational}

To improve mother's knowledge and practices for caring their infants to prevent complication. following:

The program content included the

Part 1:- An over view of LBW infants characteristics of LBW infants.
- Nutrition, sleeping, growth and development.

Part 2:- LBW care at home :Breast care . -Breast feeding position .Bottle feeding position, Diaper care Cord care -Bathing care.

The methods :Were used lecture, discussion, presentation and role play.

-Media Used flip chart, video and lap top.

It was done through 8 sessions (3theory\&5 practical), each session took one hour.

\section{Finally; the evaluating phase:}

This phase aims to study the effect of health educational program on improve mother's care of LBW infant. A post test administered to the study subjects after completion of the program, A post test was similar to pre test that was carried out before starting the program.

\section{Result:}

Table (1): Showed that, $46.7 \%$ of mothers' age ranged from 30-40 years ,Regarding the educational level, $37.7 \%$ of mothers had Illiterate level, while $80.3 \%$ of mothers were housewives. Regarding the monthly income, the present study shows that $83.6 \%$ of mothers had Un Satisfactory monthly income .

Table (2) There was improvement of all items after implementation of the program , before $(9.8 \%, 15.6 \%, 39.3 \%$, $20.5 \%, 8.2 \%, 21.3 \%, 15.6 \%, 15.6 \%)$, while after program ( $84.4 \%, 94.3 \%$, $92.6 \%, 94.3 \%, 77.9 \%, 94.3 \%, 89.3 \%$, $72.9 \%$ and There was statistical difference between before and after in all the items P.value (0.000).59\% were 
oriented about home safety, $32 \%$ about importance of breast feeding, 59\% about vaccination and $66 \%$ had correct knowledge about weaning and nutritional requirements.

Table (3) There was improvement of all items after implementation of the program , before $(19 \%, 80 \%, 36.9 \%$, $16 \%, 28.7 \%, 21 \%, 46 \%, 56.5 \%, 22.9 \%$, $20.5 \%)$, while after program ( $80 \%, 96 \%$, $88 \%, 90.2 \%, 81.9 \%, 82.8 \%, 84 \%, 96.7 \%$, $84 \%, 92.6 \%)$ and There was statistical difference between before and after in all the items P.value (0.000)

Table(4):There was improvement of all items after implementation of the program , before $(41.8 \%, 36.9 \%, 28.7 \%$, $10.7 \%, 38.5 \%, 49.2 \%, 65.6 \%, 14.8 \%)$, while after program $(83.6 \%, 90.2 \%$, $81.9 \%, 75.4 \%, 86.9 \%, 77.9 \%, 95.9 \%$, $83.6 \%$ ) and There was statistical difference between before and after in all the items P.value (0.000), Except (0.001).

Table (1). Socio-demographic characteristics for mothers of Low Birth Weight babies (NO . 122)

\begin{tabular}{|c|c|c|}
\hline & $\mathbf{N}$ & $\%$ \\
\hline \multicolumn{3}{|l|}{ Mother age : } \\
\hline$>20$ & 20 & 16.4 \\
\hline $20-$ & 45 & 36.9 \\
\hline $30-$ & 57 & 46.7 \\
\hline Mean \pm SD & 40.7 & 33.3 \\
\hline \multicolumn{3}{|l|}{ Level of education: } \\
\hline Illiterate & 46 & 37.7 \\
\hline Basic education & 35 & 28.7 \\
\hline Secondary education & 25 & 20.5 \\
\hline High & 16 & 13.1 \\
\hline \multicolumn{3}{|l|}{ Occupation: } \\
\hline Employed & 24 & 19.7 \\
\hline Housewife & 98 & 80.3 \\
\hline \multicolumn{3}{|l|}{ Monthly Income : } \\
\hline Satisfactory & 20 & 16.4 \\
\hline Un Satisfactory & 102 & 83.6 \\
\hline
\end{tabular}


Table (2). Distribution of mothers of low birth weight babies according to their knowledge about low birth weight babies before and after program (NO.122).

\begin{tabular}{|c|c|c|c|c|c|c|c|c|}
\hline \multirow{2}{*}{ Items } & \multirow{2}{*}{$\begin{array}{l}\text { Before } \\
\text { poor }\end{array}$} & \multicolumn{2}{|c|}{$100 \%$} & After & \multicolumn{2}{|c|}{$100 \%$} & \multicolumn{2}{|c|}{ Chi-square } \\
\hline & & average & good & poor & average & good & $\overline{X^{2}}$ & P-value \\
\hline $\begin{array}{l}\text { Meaning of The } \\
\text { low birth weight }\end{array}$ & 65 & 25.1 & 9.8 & 6.4 & 10.2 & 84.4 & 136.202 & 0.000 \\
\hline $\begin{array}{l}\text { The reason for the } \\
\text { birth of a child is } \\
\text { low birth weight }\end{array}$ & 80 & 4.4 & 15.6 & 1.5 & 4.24 & 94.3 & 152.558 & 0.000 \\
\hline $\begin{array}{l}\text { Spacing between } \\
\text { pregnancy reduces } \\
\text { the occurrence of } \\
\text { low birth weight } \\
\text { infants }\end{array}$ & 45 & 15.7 & 39.3 & 3.5 & 3.9 & 92.6 & 77.146 & 0.000 \\
\hline $\begin{array}{l}\text { low birth weight } \\
\text { infant's problems }\end{array}$ & 60 & 19.5 & 20.5 & 3.5 & 2.3 & 94.3 & 135.742 & 0.000 \\
\hline $\begin{array}{l}\text { The way to avoid } \\
\text { the occurrence of } \\
\text { low birth weight } \\
\text { infants }\end{array}$ & 75 & 16.8 & 8.2 & 12.5 & 9.7 & 77.9 & 120.788 & 0.000 \\
\hline $\begin{array}{l}\text { The way to avoid } \\
\text { sources of } \\
\text { infection for low } \\
\text { birth weight } \\
\text { infants }\end{array}$ & 69.2 & 9.5 & 21.3 & 1.2 & 4.6 & 94.3 & 133.080 & 0.000 \\
\hline $\begin{array}{l}\text { The best way to } \\
\text { measure the } \\
\text { infant's } \\
\text { temperature. }\end{array}$ & 57.3 & 27.1 & 15.6 & 5.3 & 5.4 & 89.3 & 133.109 & 0.000 \\
\hline $\begin{array}{l}\text { The normal range } \\
\text { of low birth weight } \\
\text { infant's } \\
\text { temperature }\end{array}$ & 48.3 & 36.1 & 15.6 & 11.8 & 15.2 & 72.9 & 81.400 & 0.000 \\
\hline
\end{tabular}


Table (3): Distribution of mothers according to their practices of home safety environment (NO.122).

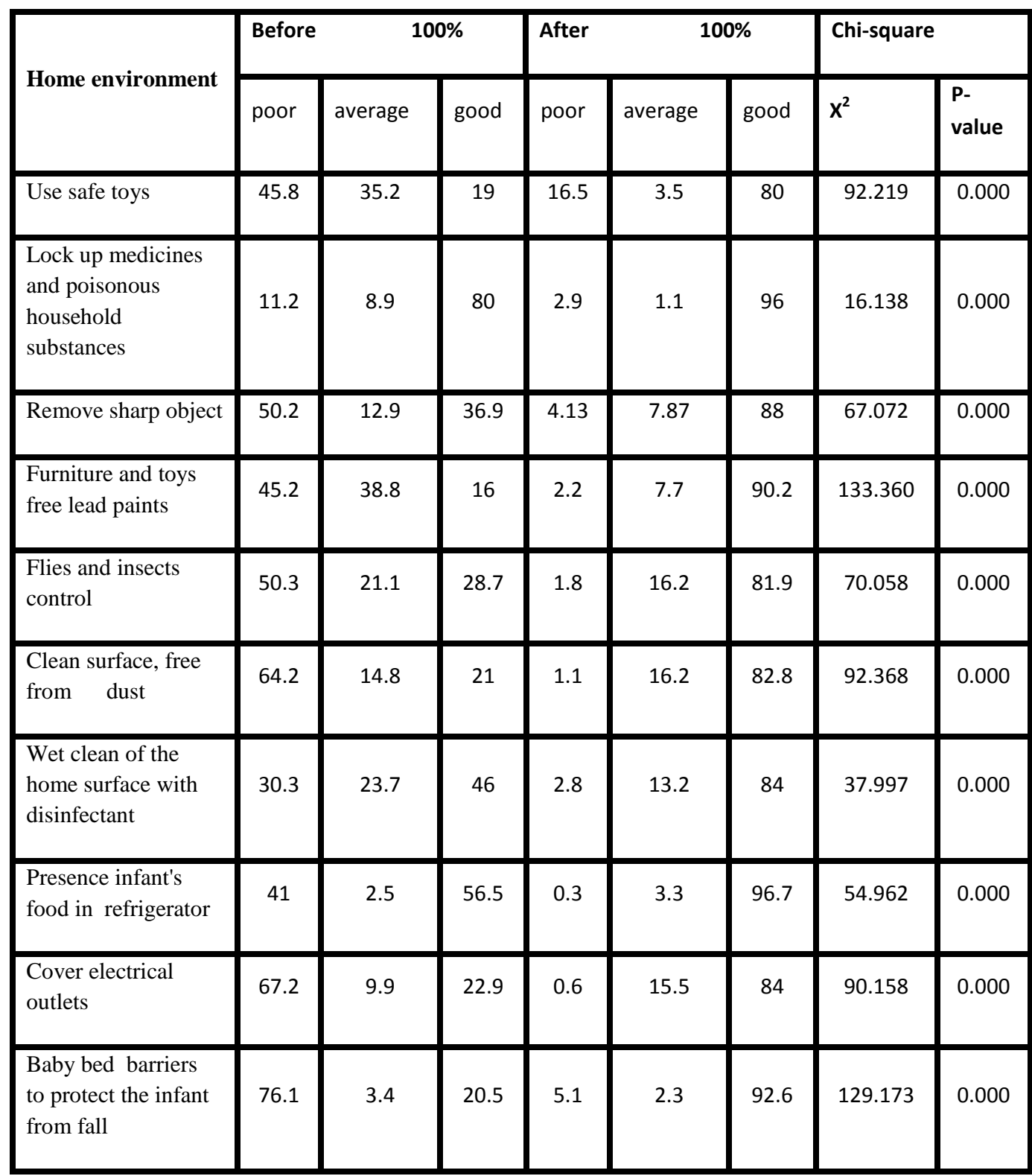


Table (4). The statistical differences between pre and post practices regarding to mothers of low birth weight babies at home care ( hygiene, nutrition, baby bath,(NO.122).

\begin{tabular}{|c|c|c|c|c|c|c|c|c|}
\hline \multirow[b]{2}{*}{ Practices } & \multicolumn{3}{|c|}{ Before } & \multirow{2}{*}{$\begin{array}{r}\text { After } \\
\text { poo } \\
\mathrm{r}\end{array}$} & \multicolumn{2}{|c|}{$100 \%$} & \multicolumn{2}{|c|}{ Chi-square } \\
\hline & $\begin{array}{r}\text { poo } \\
\mathrm{r}\end{array}$ & $\begin{array}{r}\text { averag } \\
\mathrm{e}\end{array}$ & good & & $\begin{array}{r}\text { averag } \\
\mathrm{e}\end{array}$ & $\begin{array}{r}\text { goo } \\
d\end{array}$ & $\mathbf{X}^{2}$ & $\begin{array}{r}\text { P- } \\
\text { valu } \\
\text { e }\end{array}$ \\
\hline $\begin{array}{l}\text { (Hygiene) } \\
\text { Wash your hands } \\
\text { before feed the } \\
\text { baby }\end{array}$ & 32.3 & 25.9 & 41.8 & 13.2 & 3.2 & 83.6 & 45.582 & $\begin{array}{c}0.00 \\
0\end{array}$ \\
\hline $\begin{array}{l}\text { Wash your breast } \\
\text { before feed the } \\
\text { baby }\end{array}$ & 42.7 & 20.5 & 36.9 & 7.3 & 2.6 & 90.2 & 74.730 & $\begin{array}{c}0.00 \\
0\end{array}$ \\
\hline $\begin{array}{l}\text { Time to wash the } \\
\text { breast }\end{array}$ & 51.3 & 20.1 & 28.7 & 12.7 & 12.3 & 81.9 & 70.058 & $\begin{array}{c}0.00 \\
0\end{array}$ \\
\hline $\begin{array}{l}\text { Time to burp the } \\
\text { baby }\end{array}$ & 62.2 & 27.1 & 10.7 & 18.2 & 6.4 & 75.4 & $\begin{array}{c}104.33 \\
7\end{array}$ & $\begin{array}{c}0.00 \\
0\end{array}$ \\
\hline $\begin{array}{l}\text { The way to } \\
\text { clean tools used } \\
\text { in artificial } \\
\text { feeding }\end{array}$ & 33.7 & 27.8 & 38.5 & 10.3 & 2.8 & 86.9 & 61.004 & $\begin{array}{c}0.00 \\
0\end{array}$ \\
\hline $\begin{array}{l}\text { (Nutrition ) The } \\
\text { food provided to } \\
\text { the child at fifth } \\
\text { month }\end{array}$ & 35.2 & 15.6 & 49.2 & 18.4 & 3.8 & 77.9 & 10.623 & $\begin{array}{c}0.00 \\
1\end{array}$ \\
\hline $\begin{array}{l}\text { Best way to save } \\
\text { baby's food }\end{array}$ & 18.2 & 16.3 & 65.6 & 3.1 & 1 & 95.9 & 36.077 & $\begin{array}{c}0.00 \\
0\end{array}$ \\
\hline $\begin{array}{l}\text { (Baby Bath )The } \\
\text { best time of the } \\
\text { baby shower }\end{array}$ & 68.9 & 16.4 & 14.8 & 13.5 & 2.9 & 83.6 & $\begin{array}{c}115.70 \\
3\end{array}$ & $\begin{array}{c}0.00 \\
0\end{array}$ \\
\hline
\end{tabular}

\section{Discussion}

Birth to the first 29 to 30 days of life is considered the newborn or neonate period. The normal newborn weight is between 2500 and $4000 \mathrm{gm}$ and length is between $55 \mathrm{~cm}$. Low births weights babies are those born their weights are usually less than $2500 \mathrm{gm}$.Low birth weight babies constitute a serious public health problem, which impacting families, communities, and health care services. It is associated with substantial excess of infant mortality and morbidity (American College of Obstetricians \& Gynecologists, 2015).

The study results showed that, the majority of mothers were older than 30 years, Moreover Foad (2014), who studied the factors affecting growth and development of L.B.W babies in the first year of life This result might be attributed 
to that mothers who are younger than 19 years or older than 35 years are liable to develop preterm labor and to have a low birth weight baby. So this may be views that awareness of women have to be raised through program to avoid any complication .

The study results showed that, the majority of mothers were housewives, nearly two thirds were illiterate, more than half had unsatisfactory income. This result might be illustrated that mothers' level of knowledge is the cornerstone of L.B.W babies home care, which affects on the general health condition, also the correct knowledge related to home care decreased the frequency of L.B.W baby's health problems and complications at home.

The present study showed that less than half of mothers think about of low birth weight infant's problems were decrease in body temperature but improvement after program become the majority of mothers know the problems can occur to low birth weight infant, less than tenth of mothers think about the way to avoid the occurrence of low birth weight infant was Follow-up from the beginning of pregnancy but improvement after program more than three quarter of mothers know how to avoid the occurrence of low birth weight infant ,more than quarter of mothers know the way to avoid sources of infection for low birth weight infant was good hygiene but improvement after program and became the majority of mothers know all precautions to avoid sources of infection for low birth weight infant, quarter of mothers didn't know the way to measure infant's temperature and didn't know the normal range of temperature but improvement after program and became the majority of mothers know to measure infant's temperature and the normal range of temperature .
Regarding to mother's practices of home safety environment, the study showed that less than one fifth of mothers used Furniture and toys free lead paints but improvement after program and became the majority of them used Furniture and toys should be free lead paints, more than quarter of mothers control of Flies and insects, clean the surface free from dust but improvement after program and became the majority of them control of Flies and insects ,and how clean the surface free from dust by used disinfectant, more than half of mothers kept infant's food in refrigerator but improvement after program and the majority of them did it, less than half of mothers covered electrical outlets, and used bed barriers to protect from fall out but improvement after program and became the majority of them did it . In accordance to Coffman (2014) most serious childhood accidents can be prevented. Studies showed that the mothers must be alert to certain types of accidents that may caused the greatest number of infant deaths and the community health nurse should advise mothers to begin warning about hazards that may occur to their infants .

This result must be attributed to the improvement of low birth weight mothers' level of knowledge regarding low birth weight infant's home care, which will improve the level of low birth weight infant's growth and development, moreover it will decrease the recurrence of low birth weight infant's complications.

\section{Conclusion:}

The results and research hypothesis of present study concluded that: Based on the finding of the present study it can concluded that before program The majority of mothers had poor knowledge about care of low birth 
weight neonates , most of mothers had poor practice regarding the care of low birth weight neonate ( eye care -cord care -bathing and skin care - diaper care ...etc, The program was effective in improving mother's knowledge and practice and also decreasing the complication for infants, There was statistical high significance relation between mothers' knowledge , practices and socio-demography .

\section{Recommendations}

Based on the results of the study and the previous conclusion, the following recommendations are suggested :

Health education for mothers during antenatal care especially in first trimester to avoid low birth weight infant about the meaning of low birth weight infant, the reason for the birth of baby is low birth weight, the space between pregnancy, the way to avoid sources of infection for the baby, the importance of follow up during pregnancy and guidelines for mothers contain how to deal with their low birth weight infants about care of (handling, bathing, diapering, clothing, umbilical care, feeding , sleeping, growth and development and home safety.

Further researches should be conducted to improve the mother's knowledge and practices for proper dealing with their infants because mothers play important role in the maintenance of health of newborn infants.

\section{References}

American Academy of Pediatrics Committee on Fetus and Newborn. (2012). Safe transportation of low birth weight infants. Pediatrics, 97, 758-770.
American College of Obstetricians \& Gynecologists. (2013). reproductive health \&E nvironmental pollution.(7) pp. 552-567.

American College of Obstetricians \& Gynecologists. (2015). reproductive health \&E nvironmental pollution.(6) pp. 54-72.

Ball,M.,\&Blinder,A.(2013).Mothersinfant home care drives quality in a managed care environment. J. Nurs. Care. Qual. Vol.11, No.4,pp.9-26.

Bee, H. (2014). Pediatrics, Aprimary care approach , New York, pp.716:721.

Bernbaum, S.(2012). Maternal and neonatal care. Journal of Obstetric, Gynecologic and Neonatal Nursing, 20(4), 613-701.

Blackburn, I. (2015). Premature temperature instability. Journal of Newborn Health, 503- 509.

Burrought,N.(2014). Use of Health Care Services by inner city. Infant in an early Discharge Program, Infants, Vol.109,No.6,pp. 86-90.

Brazelton,A.(2013):LowBirth Weight Infants home care .The New England Journal of Medicine, 11(3), 120.

Byenise,R. (2014): Low Birth Weight Infants home care. The New England Journal of Medicine, 99 (6), 474.

Coffman, R. (2014). Overview of premature care. Journal of Obstetric, Gynecologic, and Neonatal Nursing, 31(5), 536

Crawford, R.D., Damp bell, P., \& Ross, M. (2013): Low Birth Weight Infants 
delivery outcome. British Medical Journal, 978- 1021.

Deacon P. (2013). Essenitial Pediatrics, ivingstone,Tokyo,pp.211-216.

Edward, J., (2012): Low Birth Weight Infants home care .The New England Journal of Medicine, 19 (8), 1474.

El-Houseinie, G., \& El- Kholy.M (2014): Statistical Book, Cairo.

Evers C. (2015). Getting mothers to say yes to breast feeding (special breastfeeding issue). Childbirth Instructor, 6(4),16-20.

Foad, L. (2014). Health Effect Institute, Research Report, pp.12- 30.

KairaMkonda,D.andKhashu,D.(2013:Essenitia 1Pediatrics, 3rded.Churchill Livingstone,Tokyo,pp.44-80,83-95.

Kenner,U.,Atherton,H.,Bragg,E.,andlippert,C.( 2013):Use of hospital -based services in the first three months of life. Impact of an early discharge program. Journal of Pediatrics,Vol.130,No.2,pp.250-256.

Levene, M, Tudehope,S.(2013). Pre and postnatal care. Environmental Research, 60 (1), 30-43.

Mayo Foundation for Medical Education and Research (MFMER). (2014). Premature home care. Journal of Obstetric \& Gynecological Nursing, 37-51.

Milne, B. (2013). Premature health. Journal of Obstetric, Gynecologic.

Ministry of Health.(2010).Low birth weight infant's health. 13(5), 102-195.

Neff Spary, K. (2014). Effect of indoor pollution on the pregnant women and fetus, Journal of Emergency Medicine, 234.
Olds, S., \& Davidson, M. (2012). Maternal newborn nursing \& women health care (7th ed.). Mosby: London, pp. 760-780.

Opportunities for Africa's Newborn (2011). Common household exposure and reproductive hazards. Williams and Wilkins, Baltimore, pp. 361-378.

Osman, Z.A., \& Othman, O.A. (2014). Efficacy of social a approach on symptoms severity and adjustment among premature babies. The New Egyptian Journal of Medicine, 26 (6), 292- 301 .

Reame, N. (2014): Home care of premature newborns. Journal of Obstetric, Gynecologic \& Neonatal Nursing, 28 (3), 331-338.

Ritchie, Z. (2012). Effects of environmental pollution on preterm births in southern California. Epidemiology, 11(5), 502511.

Stoll, K., \& Chapman, L. (2009). Maternal and neonatal nursing care-family centered care. ( $3^{\text {rd }}$ ed.). J.B. Lippincott Company: Philadelphia, USA, pp. 772-779.

Wallace, M. \& Bennett, K. (2013). Preterm labor. Journal of Obstetrics \& Gynecology, 1(3), 11-55.

Ward, M. (2014).Accounting for pregnancy dependence in epidemiologic studies of low birth weight home care. Epidemiology, 9(1), 109.

Watter, A., \& Kristiansenc, R.(2014). Birth weight and prenatal mortality: The effect of gestational age. Am J Public Health, 82,378-382.

WHO/Unicef(2014). Baby Friendly initiative.National Conference of the promotion \&Protection of Breast Feeding,pp4-6. 